Kaygl, 20(I)/2021: 49-69. Araştırma Makalesi | Research Article

Makale Geliş | Received: 27.10.2020

Makale Kabul | Accepted: 19.12.2020

Yayın Tarihi | Publication Date: 15.03.2021

DOI: $10.20981 /$ kaygi.885594

Tufan KIYMAZ

Dr. Öğr. Üyesi | Assist. Prof. Dr. Bilkent Üniversitesi, İnsani Bilimler ve Edebiyat Fakültesi, Felsefe Bölümü, Ankara, TR Bilkent University, Faculty of Humanities and Letters, Department of Philosophy, Ankara, TR

ORCID: 0000-0002-6631-3857 tufankiymaz@gmail.com

\title{
Zihin Felsefesinde Fizikselin Tanımı Sorunu
}

Öz

Zihin-beden sorununun birçok felsefeci tarafından zihinselle fizikselin ontolojik ilişkisini açıklığa kavuşturma sorunu olarak ele alınması, günümüz zihin felsefesi tartışmaları için "fiziksel” teriminin tanımlanması ihtiyacını doğuruyor. Fakat, zihnin fizikselliğini sorgulanma motivasyonun altında zihnin doğasına ve doğadaki yerine dair farklı sorular yatabiliyor ve bu soruları "fiziksel" terimini kullanarak sormak istediğimizde, birbiriyle uyuşmayan, bazen de kendi içinde kabul edilebilir olmayan, farklı fiziksellik tanımlamalarını kullanmamız gerekiyor. Bu çalışmada, zihin felsefesi tartışmalarında en çok kullanılan dört fiziksellik tanımlamasını inceleyerek bu tanımlamalardaki sorunları ortaya koyuyor ve sonuç olarak, günümüz zihin felsefesinde "fiziksel" terimi diyaloğu ve anlaşmayı zorlaştıran bir rol oynamaya başladığından, zihin-beden sorunu bağlamında bu terimi kullanmaktan kaçınmanın daha yararlı olacağı görüşünü savunuyorum.

Anahtar Kelimeler: Fiziksel, Fizikselcilik, Fizik, İkicilik, Bilinç.

\section{The Problem of the Definition of Physical in Philosophy of Mind}

\begin{abstract}
Since, in contemporary philosophy of mind, the mind-body problem is generally understood as the problem of explaining the ontological relation between the mental and the physical, defining "physical" presents itself as an important issue. However, the question of the physicality of the mental can stem from several distinct underlying questions and if we want to phrase those underlying questions by using the term "physical", we are left with incompatible and, to different extents, implausible conceptualizations of the physical. In this paper, I investigate four of the most influential conceptualizations of the physical in the contemporary philosophy of mind, and I conclude that the term "physical" is best left out from the debate on the mind-body problem.
\end{abstract}

Keywords: Physical, Physicalism, Physics, Dualism, Consciousness. 


\section{Giriş}

Düşüncecilik (idealism), yani varlığın temelde düşünce olduğu görüşü ve maddecilik (materialism), yani varlığın temelde madde olduğu görüşü arasındaki tartışma günümüz zihin felsefesinde yerini fizikselcilik (physicalism) ve ikicilik (dualism) tartışmasına bırakmış durumda. Düşüncecilik ve maddecilik, varlığın özünde tek bir temel ontolojik kategoriye indirgenebileceğinde, yani tekçilikte (monism) hemfikir olmakla birlikte bu temel ontolojik kategorinin gerçeklikte zihinden bağımsız var olup olamayacağı konusunda karşıt görüşe sahipti. Maddenin varlığg ve düşünceden ontolojik bağımsızlı̆̆ı günümüzde genel kabul gördüğünden, güncel zihin felsefesi literatüründe düşüncecilik kabul edilebilir bir tekçi alternatif olarak karşımıza çıkmıyor. Bir zamanlar düşünceciliğin rakibi olan maddecilik de yerini fizikselciliğge bırakmış durumda. Bunun sebebi, günümüz bilimine göre maddeden ibaret olmayan, fakat maddeyi etkileyen, fiziksel alanlar, uzay-zaman sürekliliği, karanlık enerji gibi fiziksel fenomenlerin varlığı. Bu anlamda, günümüzün başat tekçi görüşü, gerçek dünyada örneklenen her özelliğin fiziksel (ya da işlevsel veya yapısal olup örneklenmesi ontolojik olarak fiziksel özelliklerin örneklenmesine indirgenebilecek olan) bir özellik olduğunu iddia eden fizikselcilik görüşü. Bu görüşe göre, bilinçli zihin özellikleri ve bu özelliklerin örneklendiği zihin durumları da fizikseldir (ya da fiziksele indirgenebilir). Töz ikiciliği, özellik ikiciliği gibi farklı türlere sahip olan ikicilik görüşünü bu çalışmada sadece şu iki iddianın toplamı olarak ele alacağım: (1) Gerçek dünyada örneklenen fiziksel özellikler vardır. (2) Gerçek dünyada örneklenen fakat ontolojik olarak fiziksel özelliklere indirgenemeyecek olan bazı özellikler de vardır. İkiciler tarafından fiziksele indirgenemeyeceği en yaygın olarak iddia edilen özellikler “görüngüsel (phenomenal) özellikler” dediğimiz, bilinçli zihin durumlarının nitel özellikleridir.

Zihin felsefesinde merkezi bir yeri olan bilinçli zihnin ontolojisi sorunu, pratikte, zihnin son tahlilde fiziksel olup olmadığını belirleme sorununa denk düşüyor. Fakat, burada önemli bir soru kendini gösteriyor: "Fiziksel” ne demektir? Yani, "zihin fiziksel 
midir?" sorusunu sorduğumuzda, aslında neyi soruyoruz? Eğer zihnin fiziksel olduğunu (ya da olmadığını) öğrenseydik, bu bize zihnin doğasına dair nasıl bir anlayış katardı? Bu çalışmada, öncelikle, "fiziksel" teriminin günümüz zihin felsefesi literatüründe bulunabilecek dört farklı tanımlamasını inceleyeceğim. Bunlar sırasıyla kuramcı tanımlama, örnekçi tanımlama, via negativa tanımlama ve konumcu tanımlama olarak adlandırılabilir. Kısaca, "fiziksel özellik” terimi, kuramcı tanımlamada fizik biliminin (ya da fiziksel bilimlerin) kuramlarına atıfta bulunarak; örnekçi tanımlamada fiziksel olduğu apaçık olan bazı paradigmatik nesne ya da özelliklere dayanarak; via negativa tanımlamada indirgenemez zihinsellik ile karşıtlık kurularak; konumcu tanımlamada ise mekansallık ile tanımlanır. Bu tanımlamaların hiçbirinin "fiziksel" terimine zihin felsefesi bağlamında tam anlamıyla doyurucu bir tanım getiremediklerini ve, alternatif bir yaklaşım olarak, "fiziksel” terimini kullanmadan zihin-beden problemini farklı şekillerde yeniden formüle etmenin pragmatik açıdan daha doğru olacağı görüşünü savunuyorum.

\section{Kuramci Tanımlama}

Fizikselliğin kuramcı tanımlamalarına göre, bir özelliğin fizikselliği ondan, ya da onun indirgenebileceği özelliklerden, fizik biliminin (ya da fiziksel bilimlerin) kuramlarında söz edilmesine dayanır. Stoljar'ın "kuram temelli kavramsallaştırma” (theory-based conception) olarak adlandırdığı tanımlama, kuramcı tanımlamanın standart formülasyonu olarak ele alınabilir: “fiziksel bir özellik ya fiziksel kuramın bahsettiği ya da fiziksel kuramın bahsettiği özelliklere metafiziksel olarak bağımlı olan özelliktir" (Stoljar 2001: 257).

David Armstrong, fizikselciliği "uzay-zaman dünyasının tamamlanmış bir fizik tarafından tanınan varlık ve kanunlarlardan ibaret olduğunu iddia eden öğreti” olarak tanımladığında fizikselin kuramcı bir tanımını kullanıyor (Armstrong, 1993: 434). Benzer bir şekilde, Armstrong (1970) zihin felsefesi bağlamında fizikselciliği şu hipoteze dayanarak formüle ediyor: "Fiziksel-kimyasal hipotez: İnsanın tamamlanmış bir açıklamasının sadece fiziksel-kimyasal terimlerle ifade edilebileceği görüşü.” 
Frank Jackson'ın, “tamamlanmış fizik, kimya ve nörofizyolojide bahsedilen her şey ve işlevsel roller de dahil olmak üzere, bütün bunlara dayanan nedensel ve ilişkisel olgulara dair bilinebilecek şeylerin tümü’nün fizikselin tamamlanmış bilgisini oluşturduğu ve bunlar içinde yer almayan doğruların varlığının fizikselciliği yanlışlayacağı iddiası da fizikselin kuramcı tanımlamasına dayanıyor. (Jackson, 1986: 291)

$\mathrm{Bu}$ alıntılardan görülebileceği üzere, kuramcı tanımlama fizik bilimine ya da daha genel olarak, kimya, biyoloji, nörofizyoloji gibi bilimleri de içerecek şekilde fiziksel bilimlere atıfla karakterize edilebilir. Ben tartışmayı basitleştirmek adına bu çalışmada fizik bilimine dayanan tanımlamaya odaklanacağım, fakat bu tanımlamaya karşı ele alacağım itirazlar fiziksel bilimlere dayanan tanımlamalara da uyarlanabilir itirazlar olacak.

Kuramcı tanımlamaya karşı en etkili itirazlardan biri Melnyk (1997) tarafından Hempel'e atfedilen ve literatürde "Hempel İkilemi" olarak adlandırılan şu itirazdır: kuramcı tanımlamayı kabul edersek, fizikselin ne olduğunu ya günümüz fiziğinin kuramlarına ya da tamamlanmış/ideal fiziğin kuramlarına göre tanımlamamız gerekir, fakat bu seçeneklerin hiçbiri fizikseli tanımlamamıza yardımcı olamaz çünkü güncel fizik kuramlarımız büyük ihtimalle yanlıştır ve ideal fiziğin neye benzeyeceğini bilemiyor olmamızdan dolayı ideal fiziğe atıfla yapılan bir fiziksellik tanımlaması içerikten yoksun olacaktır.

Hempel İkilemi’nin iki koluna sırasıyla bakalım.

\section{1. Güncel Kuramcı Tanımlama}

Fizikseli tanımlamakta günümüz fiziğinin kullanılması sorunlu görünüyor, çünkü, geçmişteki birçok fizik kuramının daha sonra yerini yeni ve açıklama/öndeyi gücü daha yüksek olan bir kurama bırakmış olması, bize günümüzün fizik kuramlarının da gelecekte yerlerini daha başarılı kuramlara bırakacaklarını düşünmek için iyi bir sebep veriyor (kötümser üst-çıkarım). Fakat, fizik kuramlarımızın gelecekte değişecek 
olmasını kabul etmek demek, günümüz kuramlarının yanlış, ya da en azından eksik olduğunu kabul etmek anlamına geldiğinden, fizikselin tanımını günümüz kuramlarına atıfla yaparsak, bu tanımın da yanlış ya da eksik olacağını kabul etmemiz gerekiyor, ki bu durumda fizikseli günümüz fiziğine atıfla tanımlamak makul bir seçenek olarak karşımıza çıkmıyor.

Bu itiraza yanıt olarak, Smart (1978: 340) ve Bokulich (2011) gibi bazı felsefecilerin görüşleri doğrultusunda, şöyle bir iddiada bulunulabilir: Eğer fizikselcilik doğruysa bilinç durumları beynin nörolojik durumlarına, yani, son tahlilde, günümüzde aşina olduğumuz maddeye indirgenebilir, ve geleceğin fiziğinde bahsedilebilecek olan yeni egzotik varlık ya da özelliklerin fizikselcilik-ikicilik tartışmasına bir etkisi olmayacaktır, bu yüzden de fizikselin tanımında güncel fiziğin kullanılması zihin felsefesi bağlamında bir sorun teşkil etmeyecektir. Ben güncel kuramcı tanımlamanın bu savunusunu başarılı bulmuyorum, çünkü nöron-altı ya da nöron-dışı fiziksel durumların bilinç durumlarını etkilemediği iddiasını kabul etmek için yeterli veriye sahip olduğumuzu düşünmüyorum. Günümüz fiziğinin tüm kuramları, evrenimizde var olduğunu düşündügümüz şeylerin yalnızca \%5'ine dair ve evrenimizde var olan şeylerin yaklaşık \%25'ini oluşturduğunu düşündügümüz karanlık madde ve kalan \%70’i oluşturduğunu düşündügümüz karanlık enerjiye dair henüz günümüz fiziğinde kabul edilmiş bir kurama sahip değiliz. Günümüz fiziği ve nörobilimi evrenimizdeki varlıkların \%95'ini oluşturan karanlık madde ve karanlık enerjinin zihinsel olgularda bir rol oynadığına inanmak için bize pozitif bir sebep sunmasa da, bu \%95'lik gizemin zihinsel olgulara hiçbir etkisi olmadığına inanmak için de yeterli sebebimiz olmadığını düşünüyorum. Şu anda hem fizik bilimi hem de zihin felsefesi açısından bulunduğumuz noktada, gelecekteki fizik biliminin günümüzde tahmin edemediğimiz bulgularının, bilinçli zihinsel durumlarımızın doğasına dair anlayışımızı değiştirmeyeceğine dair bir güven temelsiz duruyor.

Bunun da ötesinde, günümüz fiziğinde yer alan, sıradan madde ve enerjiye dair kuramların bazılarının yanlış olduğundan da emin olabiliriz, çünkü günümüz fiziği, tamamlanmış bir fizikten beklenecek olanın aksine, tutarlı bir bütün oluşturmuyor. 
Örneğin De Broglie'nin öncü dalga kuramı günümüzde genel kabul görmese ve standart kuantum mekaniğiyle uyuşmasa da öncü dalga kuramının varyasyonları ya da kuantum mekaniğine Bohmcu yaklaşımlar bugün hala canlılı̆̆ını koruyor (Goldstein 2017). Aynı durum standart kuantum mekaniği ve genel görelilik teorisinin küçük boyutlardaki yüksek enerji durumlarında tutarsız sonuçlar vermesinde de gözlemlenebiliyor. Günümüz fiziğindeki bazı kuramların birbirleriyle tutarsız olması, fizikseli günümüz fizik kuramlarına atıfla tanımlama girişimi için önemli bir sorun yaratıyor.

\section{2. İdeal Kuramcı Tanımlama}

Hempel ikilemine göre, ikinci seçeneğimiz fizikseli günümüz fiziği yerine ideal/tamamlanmış fiziğe atıfla tanımlamak. Fizikselcik hakkındaki tartışmalar sırasında fizikselin kuramcı tanımlamasını kullanan birçok felsefeci, örneğin Armstrong (1993), Jackson (1982), Chalmers \& Jackson (2001: 316) ve Loewer (2001: 37), fizikseli tamamlanmış fiziğe atıfla tanımlamayı tercih ediyor. Fakat, bu seçenekte de şöyle bir sorun göze çarpıyor: İdeal/tamamlanmış fiziğin ne gibi varlık veya özelliklerden bahsedeceğini şimdiden öngöremiyoruz ve "fiziksel” teriminin tamamlanmış fizik gibi hakkında yeterince bilgi sahibi olmadığımız bir şeye atıfla yapılan tanımı "fiziksel" teriminin anlamını açıklığa kavuşturmaktan çok uzak olacaktır; bilgi vermeyen, kapalı, kullanışsız bir tanım olacaktır. Bu kapalılık, Noam Chomsky’e (1995) göre, “fiziksel” teriminin zihin felsefesindeki kullanımına dair önemli bir sorun yaratıyor: Chomsky tamamlanmış fizikte temel/indirgenemez bilinç özelliklerinden bahsedilmesinin mümkün olduğunu iddia ediyor, ki bu durumda indirgenemez bilinç özellikleri fiziksel olacaktır, fakat indirgenemez bilinç özelliklerinin (mesela Kartezyen ruhun bilinç özellikleri gibi) varlığının fizikselcilikle uyuşmadığı görüşü günümüz zihin felsefecileri tarafından yaygın olarak kabul ediliyor. Örneğin, Thomas Nagel'in (1974), henüz keşfedemediğimiz nesnel fenomenolojik bir dille belli bir deneyimin nasıllığını o deneyime sahip olmayan bir insana, deneyimi hayalinde canlandırmaya ihtiyaç duymadan anlayabileceği şekilde ifade edebilmenin mümkün olabileceğine dair görüşü doğruysa, bilinçli deneyimlerin nesnel bilgisinin var olması ve bu bilginin tamamlanmış 
bir fizikte içerilmesi mümkün. Chomsky’nin tamamlanmış fizik hakkındaki iddiası kuantum fiziğinin Kopenhag yorumunu göz önünde bulundurduğumuzda daha da ciddileşiyor. Örneğin, Bohr (1934, 1958), Heisenberg (1958), and Von Neumann (1955)'ın çalışmaları doğrultusunda, Henry Stapp (2007), ortodoks kuantum kuramının Kartezyen, etkileşimci ikici bir kuram olduğunu iddia ediyor. Chomsky’e göre, şu anda bildiklerimize dayanarak, indirgenemez bilinç özelliklerine atıfta bulunan böyle bir kuramın tamamlanmış fizikte yer bulmayacağından kesin olarak emin olamayız ve bu, Poland'ın (2003) deyişiyle, “zihinselin fiziksele inzali” olasılığı, tamamlanmış fiziğe dayanan bir "fiziksel" tanımını "zihin fiziksel midir?" sorusu üzerinde tartışan felsefeciler için tamamen kullanışsız hale getiriyor ${ }^{1}$.

$\mathrm{Bu}$ itiraza yanıt olarak, kuramcı tanımlamanın savunucuları tamamlanmış fizikte bahsedilmeyi fiziksel olmanın gerekli fakat yeterli olamayan bir koşulu olarak kabul edip, ikinci bir gerekli koşul öne sürebilirler, öyle ki, fiziksellik için, bu iki gerekli koşul birlikte yeterli olur. Yani, bu durumda, tamamlanmış fizikte bahsedilen her özellik tanımı gereği fiziksel olmayacak, tamamlanmış fizikte bahsedilen ve bir diğer özelliğe sahip olan özellikler fiziksel sayılacaktır. Günümüz zihin felsefesi literatüründe ideal kuramcı tanımlamayı desteklemek için en sık kullanılan koşul olarak "indirgenemez bir şekilde zihinsel olmama" koşulu karşımıza çıkıyor. İdeal kuramcı tanımlamanın bu versiyonuna "via negativa ideal kuramcı tanımlama" adını verebiliriz.

\section{3. Via negativa İdeal Kuramcı Tanımlama}

Fiziksel özelliği zihinsel-olmayana ontolojik olarak indirgenebilir özellik olarak alan tanımlama, literatürde "via negativa tanımlama” olarak adlandırılıyor. Tye (2009), Chalmers ve Jackson (2001) ve Wilson (2006) da, zihinselin fiziksele inzali itirazına karşılık olarak, ideal kuramcı tanımlamayı via negativa tanımlama ile destekleyebileceğimizi iddia ediyor. Böylece, şu tanımlamaya ulaşıyoruz: Bir özellik

\footnotetext{
1 Chomsky’nin itirazınının, psikolojinin fiziksel bilimlere dahil olup olamayacağı sorusu gündeme getirilerek, özelde fizik bilimine değil genel olarak fiziksel bilimlere atıfta bulunan kuramcı tanımlaya uyarlanması için bkz. Crane \& Mellor (1990).
} 
fizikseldir ancak ve ancak tamamlanmış fizikte kendisinden bahsedilen zihinsel olmayan temel bir özellik ise ya da böyle özelliklere indirgenebilir ise.

Fakat, bu tanımlamada da bazı sorunlar var. Öncelikle, elektrik yükü, kütle, spin gibi birçok fiziksel özelliğin hem makro hem de mikro boyutta örneklemeleri bulunuyor. Yani, makro boyutta fiziksel saydığımız bir özelliğin indirgenemez bir şekilde temel bir parçacık tarafından örneklenmesi özelliğin fizikselliğini etkilemiyor. Negatif elektrik yüküne sahip olma özelliğini ele alalım. Bu özellik (sicim kuramını değil standart kuramı kabul edersek) bir elektron tarafından temel ve indirgenemez bir şekilde örnekleniyor, fakat bir yün kazak tarafından makro boyutta, temel ve indirgenemez olmayan bir şekilde örnekleniyor. Bu iki örneklemenin arasındaki temel olma-olmama farkı bu özelliğin doğasına, fizikselliğine dair hiçbir ontolojik öneme sahip değil. O halde, fizikselcilere göre makro boyutta fiziksel olan bilinç özelliklerinin mikro boyutta, indirgenemez bir şekilde örneklenmeleri neden onların fizikselliğini olumsuz etkilesin? Temel ve temel olmayan örneklemeleri olan birçok fiziksel özellik varken bilinç özelliklerinin temel ve temel olmayan örneklemeleri arasında fiziksel olma ve olmama kadar büyük bir ontolojik fark olacağını düşünmek için sebebimiz nedir?

Bundan da önemlisi, ideal kuramcı tanımlama, indirgenemez zihinselliğin reddi koşuluyla desteklense dahi, temel bir soruna sahip. Buna "örneklenmeyen özellik" sorunu diyebiliriz. İdeal kuramcı tanımlamaya göre, gerçek dünyada örneklenmeyen ve dolayısıyla ideal/tamamlanmış fizikte bahsi geçmeyen (ve ideal/tamamlanmış fizikte bahsi geçen özelliklere indirgenemeyen) hiçbir özelliğin fiziksel özellik olması mümkün değil. Geçmişte doğru kabul edilip bugün yerini daha başarılı kuramlara bırakmış olan fizik kuramları ve bu kuramlarda bahsedilen, fakat günümüz fiziğinde (ve çok büyük ihtimalle ideal fizikte de) yer bulamayan özellikler mevcut. Fakat, en azından sezgisel olarak, denebilir ki eğer bir kuram fiziksel olmayan şeylere atıfta bulunuyorsa, bu kuram bir fizik kuramı sayılamaz. Eğer bu doğruysa, ideal kuramcı tanımlamanın şöyle bir sonucu ortaya çıkıyor: etere, filojistona, kalorike, mutlak zaman ve mutlak uzaya atıfta bulunan hiçbir kuram, bu kuramların ideal fizikle örtüşmediğini kabul edersek, 
fizik kuramı sayılamaz. Fakat, bir kuramın yanlışlığının onun fizik kuramı olup olmamasını etkilemesi çok makul gözükmüyor. Daha da önemlisi, yukarıda da değindiğimiz gibi, çok büyük bir olasılıkla günümüz fiziği ileride güncellenecek ve ideal fizik günümüz fiziğinden belki de çok farklı olacak. Bu durumda, büyük ihtimalle, şu anda fizik kuramlarımızda bahsedilen bazı özelliklerden ideal fizikte bahsedilmeyecek. Ve bu da, ideal kuramcı tanımlamanın bir sonucu olarak, günümüz fizik kuramlarının aslında fizik kuramı olmadığı anlamına geliyor, çünkü bu kuramlarda, büyük ihtimalle, gerçekte örneklemesi olmayan ve dolayısıyla da ideal kuramcı tanımlamaya göre fiziksel olmayan özelliklerden bahsediliyor. Günümüz fiziğinde bahsedilen bazı özelliklerden ideal fizikte bahsedilip edilmeyeceğine dair olasılıksal bir yargıda bulunmasak dahi, ideal kuramcı tanımlamanın şunun gibi karşıolgusal sonuçları da kabul edilebilir durmuyor: Diyelim ki görelilik teorisi aslında doğru, fakat eğer yanlış olsaydı, eğer görelilik teorisinde bahsedilen uzay-zaman sürekliliği gerçekte var olmasaydı ve aslında uzay ve zaman daha çok Newtoncu fiziğin betimlemelerine uygun olsaydı, görelilik teorisi fiziksel olmayan şeylere atıf yapan bir kuram olacaktı, ve dolayısıyla da bir fizik kuramı olmayacaktı.

Güncel veya ideal fiziğe atıfta bulunan, via negativa koşulu ile desteklenen ya da desteklenmeyen tüm kuramcı tanımlamalara bir diğer itiraz da bilim felsefesinde "ayırdetme sorunu" (demarcation problem) olarak bilinen soruna dayanarak yapılabilir. Şöyle düşünebiliriz: Eğer bir kuram bilimsel bir kuram değilse (örneğin, astroloji ya da homeopati gibi sahtebilimsel bir kuramsa), bu kuram fizikselin tanımlanmasında kullanılabilecek bir fizik kuramı olamaz. Sicim kuramını ele alalım. Bazı bilim felsefecileri ve biliminsanları, sicim kuramının prensipte empirik olarak test edilemez bir kuram olduğu kabulünden yola çıkarak, Popperci bir yaklaşımla, sicim kuramının bilimsel bir kuram sayılamayacağını iddia ediyor. Eğer bu iddia doğruysa ne güncel ne de tamamlanmış fizik sicim kuramını içerecektir ve bu yüzden de sicimler, gerçekten var olsalar dahi, kuramcı tanımlamaya göre, fiziksel sayılamayacaktır. Bu durumda, fizikselin kuramcı tanımlamalarının başarısı ayırdetme sorununun çözümüne bağlı gibi gözüküyor. Fakat ayırdetme sorunu, Derksen'in (1993) de dikkat çektiği üzere, bilimin 
zaman içinde değişmesi, heterojen olması ve yerleşik bilimde de sahtebilimin kusurlarından bazılarının görülebilmesi sebebiyle bilim felsefesindeki en tartışmalı konulardan biri olduğundan, bir kuramın bilimselliğinin ayırdetme sorununun çözümüne dayanması neticesinde fizikselin kuramcı tanımlamaları da en az ayırdetme sorunu kadar tartışmalı hale geliyor.

Bu noktada vurgulamak isterim ki, kuramcı tanımlamayı fizik bilimi yerine genel olarak fiziksel bilimlere atıfla formüle etmek yukarıdaki itirazlar karşısında bir ilerleme kaydetmeyecektir. Güncel ya da ideal fizik biliminin fizikselin tanımlanmasında kullanılmasına getirilen eleştiriler güncel ya da ideal fiziksel bilimlerin kullanılmasına da rahatlıkla uyarlanabilir, çünkü bu itirazlar bahsettiğimiz kuramların fizik kuramları olmalarından çok bilimsel kuramlar olmalarına dayanıyor ${ }^{2}$.

Belki de fizik biliminin ya da fiziksel bilimlerin kuramlarına hiç atıfta bulunmadan, bu kuramların açıklamaya çalıştığı şeylere, yani fiziksel olduğu bariz olan şeylerin doğalarına ve temel yapı taşlarına atıfta bulunarak fizikseli tanımlayabiliriz. Şimdi bu alternatifi değerlendirelim.

\section{2. Örnekçi Tanımlama}

Görüngüsel bilinci, yani bir zihin durumunun birinci kişi gözünden deneyimlenen nasıllığını, niteyi (qualia/quale) nasıl tanımlayabiliriz? Felsefi terminolojiye aşina olmayan bir okuyucuya görüngüsel bilinçten ne kastettiğimizi anlatmanın en basit (belki de tek) yolu, okuyucuyu kendi deneyimlerinin öznel niteliğine odaklanmaya davet etmek olacaktır. Yani, "görüngüsel bilinç” terimiyle ne kastettiğimizi açıklığa kavuşturmak için, okuyucuyu bilinçli bir zihin durumuna, mesela diş ağrısının ya da

\footnotetext{
${ }^{2}$ Kuramcı tanımlamaya dayanan fizikselci görüşlerin ortak noktası, birinci kişi gözünden algıladığımız görüngüsel gerçeklerin bilimsel/nesnel dille de ifade edilebileceği iddiasıdır. Kuramcı tanımlamayı kabul eden a priori fizikselciler, görüngüsel gerçeklerin öznel bilgisinin tamamlanmış bilimsel bilgiden a priori olarak türetilebileceğini iddia ederken, a posteriori fizikselciler böyle bir a priori çıarımın mümkün olmadığını, fakat yine de her görüngüsel gerçeğin aynı zamanda bilimsel/nesnel dille de ifade edilebileceğini iddia ederler. Kuramcı tanımlamaya dayanan a priori fizikselciliğin bir değerlendirmesi için bkz. Kıymaz (2020). Kuramcı tanımlamaya dayanan (ve görüngüsel kavram stratejisini kullanan) a posteriori fizikselciliğin bir değerlendirmesi için bkz. Kıymaz (2019a). Ayrıca, kuramcı tanımlamaya dayalı fizikselcilik anlayışlarına bir itiraz olarak ortaya çıkan öznel fizikselcilik görüşünün bir değerlendirmesi için bkz. Kıymaz (2019b).
} 
elmanın tadının bilinçli hissine odaklanmaya davet edip, okuyucu o durumu birinci kişi gözünden deneyimlerken ya da deneyimlediğini hayal ederken "işte şu anda deneyimliyor olduğuna benzer zihin durumlarından bahsediyorum" diyebiliriz. Peki, “fiziksel”den ne kastettiğimizi de benzer bir şekilde açıklığa kavuşturamaz mıyız? Diş ağrısı ve elmanın tadı deneyimleri gibi bariz görüngüsel bilinç durumu örneklerinden hareketle "görüngüsel bilinç"i kavramsallaştırdığımız gibi, bariz bir şekilde fiziksel olan nesne, özellik ya da olgulara atıfla "fiziksel"i tanımlayamaz mıyı? Daniel Stoljar (2001), “fizikselin örnekçi tanımlaması" diyebileceğimiz bu stratejiyi şu şekilde uyguluyor:

Fiziksel bir özellik ya paradigmatik fiziksel nesnelerin ve bu nesnelerin yapı taşlarının içkin doğasını açıklamak için gerekli olan ya da paradigmatik fiziksel nesnelerin ve bu nesnelerin yapı taşlarının içkin doğasını açıklamak için gerekli olan özelliklere metafiziksel olarak bağımlı olan özelliktir. (Stoljar 2001: 257)

Stoljar, bu tanımlamada temel alınacak fiziksel nesnelere örnek olarak taşlar, ağaçlar ve gezegenleri veriyor (2001: 257). Jackson (2000) da şöyle bir örnekçi tanımlama öneriyor:

Fizikselciler, "fiziksel özellikler ve ilişkiler" ile ne kastettiklerini masalar, ağaçlar, dağlar gibi bilinçsiz nesne örneklerine (exemplar) işaret edip fiziksel özellik ve ilişkilerin bu nesnelerin tamamlanmış açıklamasını sunabilmek için gerekli özellik ve ilişkiler olduğunu söyleyebilirler. (Jackson 2001: 7)

Benzer şekilde, Snowdon fiziksel olmayı "algılanmadan da var olabilmek, mekânda var olmak gibi özelliklere sahip bu nesneler (mesela masalar ve ağaçlar) temelde nasılsa öyle olmak şeklinde" açıklayabileceğimizi söylüyor. (Snowdon 1989: 153)

Fakat, örnekçi tanımlamaların temelinde ciddi bir sorun var, bu yüzden de zihin felsefesi literatüründe kuramcı tanımlamalardan çok daha az rağbet görüyorlar. Yukarıdaki alıntılarda fizikselliğe örnek teşkil edecek olan nesneler olarak taşlar, ağaçlar, masalar, dağlar ve gezegenlerin verildiğini görüyoruz. Bunları ve bunlara benzeyen nesneleri ve onların içkin doğalarını açıklayan özellikler de fiziksel özellik olarak kabul ediliyor. Fakat, bu listenin yeterince kapsayıcı olduğuna emin olabilir 
miyiz? Örneğin, karanlık madde spiral galaksilerde yıldızların nasıl savrulmayıp bir arada kaldıklarını açıklamak için, karanlık enerji ise galaksilerarası uzayın ivmeli genişlemesini açıklamak için ortaya atılmıştı fakat spiral galaksiler ve galaksilerarası uzay taşlar, ağaçlar, masalar, dağlar ve gezegenlerin olduğu listede yer almıyor, bu durumda, karanlık madde ve karanlık enerji, bu örnekçi tanımlamaya göre, fiziksel olamaz. Tabii ki spiral galaksileri ve galaksilerarası uzayı da bu listeye dahil edebiliriz, fakat sorun şu ki hiçbir zaman bu listenin tamamlanmış olduğundan emin olamayız. Karanlık madde ve karanlık enerjiyi postüle etme ihtiyacımız doğmadan önce spiral galaksileri ve galaksilerarası uzayı fizikselin örnekleri listesine dahil etmemiz için bir sebebimiz yoktu, şimdi de ileride bu listeye neleri dahil etmemiz gerekeceğini öngörmemiz imkânsız görünüyor. Hatta, Chomsky’nin kuramcı tanımlamaya getirdiği “zihinselin fiziksele inzali” itirazını örnekçi tanımlamaya uyarlayabilir ve ileride bu listeye zihinlerin dahil edilip edilmeyeceğinden de emin olamayacağımızı ve bu yüzden de fizikselin örnekçi tanımlamanın zihin felsefesinde kullanılmaya uygun olmadığını söyleyebiliriz.

Bunun da ötesinde, eğer Kartezyen (etkileşimci) bir ruha sahipsek ve ruh ile olan etkileşimi beynimizin işleyişinde metafiziksel olarak vazgeçilmez bir rol oynuyorsa, beynimiz örnekler listesindeki fiziksel nesnelere benzerliği nedeniyle fiziksel sayılacağından ve beynin (en azından Descartes'e göre "ruhun tahtı" olan epifiz bezinin) tamamlanmış açıklaması ruha atıfta bulunmadan yapılamayacağından, Kartezyen ruh da bu tanımlamaya göre fiziksel olacaktır. Benzer bir şekilde, eğer vesilecilik (occasionalism) doğru ise, yani maddede gerçek anlamda nedensellik yoksa ve her oluşun tek nedeni Tanrı'nın iradesi ise, gözlemlediğimiz tüm nesne ve olguların tamamlanmış açıklamasında Tanrı'ya atıfta bulunulması gerekecektir ve bu durumda da örnekçi tanımlamaya göre zaman ve mekândan münezzeh Tanrı'nın fiziksel bir varlık olarak kabul edilmesi gerekecektir. Bunlar gibi olası senaryolar örnekçi tanımlamaya karşı reductio argümanlar olarak sunulabilir ${ }^{3}$

\footnotetext{
${ }^{3}$ Örnekçi tanımlamanın daha ayrıntılı bir analizi ve eleştirisi için bkz. Kıymaz (Yayınlanacak)
} 


\section{Via negativa Tanımlama}

Bir diğer alternatif olarak, daha önce kuramcı tanımlamayı Chomsky'nin itirazına karşı desteklemek için kullanıldığından bahsettiğimiz via negativa koşulunu bağımsız bir tanımlama olarak ele alabiliriz. Howell (2008), Levine (1983), Göcke (2009), Spurrett and Papineau (1999), Montero (1999), Cornman (1971) ve Smith (1993) gibi birçok felsefeci fizikselciliğin özünü zihinselin ontolojik olarak temel (fundamental) olmadığı ve zihinsel-olmayandan türediği iddiası olarak yorumluyor. Bu iddiaya dayanan via negativa tanımlamaya göre bir özelliği fiziksel yapan, indirgenemez (temel/fundamental) bir şekilde zihinsel olmamasıdır.

Via negativa ideal kuramcı tanımlamayı sorgularken de gördüğümüz üzere, diğer fiziksel özelliklerde indirgenebilirlik ve indirgenemezliğin fiziksel olup olmamak kadar ciddi bir ontolojik sonucunun olacağı iddiası ad hoc bir varsayım gibi duruyor. Fakat, eğer fizikseli zihin felsefesi tartışmaları için tanımlamaya çalışıyorsak ve zihinselin zihinsel-olmayana indirgenip indirgenemeyeceği fizikselciler ve ikiciler arasındaki temel bir fikir ayrılığına işaret ediyorsa, fizikselin temelde zihinsel-olmayan olarak anlaşılması, genel olarak ad hoc olsa da zihin felsefesi bağlamında makul gözükebilir. Burada bir kaygı, fiziksel teriminin değişik alanlardaki kullanımı arasındaki bütünlüğün kaybı olabilir. Örneğin, "zihin fiziksel mi?" sorusu bağlamında "fiziksel" temelde zihinsel-olmamakla tanımlanacaksa, bir zamanlar tartışılmış olan "canlılık fiziksel mi?" sorusu bağlamında da "fiziksel" temelde canl1-olmamakla tanımlanacaktır. Bu durumda da fiziksel terimi genel bir ontolojik türe göndermede bulunmaktan çok, fizikselliği sorgulanan her x cinsi için x-olmayan anlamına gelecek bir yer tutucuya dönüşecektir. $\mathrm{Bu}$ alamda da via negativa tanımlamanın gerçek anlamda fizikselliğin bir tanımlaması olduğunu söylemek güçleşiyor. Ancak, bu çalışmada fizikselliği zihin-beden sorunu bağlamında ele alıyoruz ve zihinselin ontolojik indirgemezliği fizikselcilerle ikiciler arasında önemli bir ayrışma noktası olduğundan, via negativa tanımlamanın zihin felsefecilerince pragmatik sebeplerle kabul edilmesinin büyük bir sorun yaratmayacağını düşünüyorum. 
Fakat, fizikselcilerle ikiciler arasında zihnin indirgenemezliği dışında başka ayrışma noktaları da var. Örneğin, Descartes için zihinseli fizikselden (ya da daha doğrusu maddeden) ayıran şey zihnin özünde düşünmenin olması fakat uzayda yer kaplamanın olmamasıyd. Descartes'in res extensa'sını fiziksel olarak yorumlarsak, konumcu tanımlama olarak adlandırabileceğimiz bir tanımlamanın bir versiyonunu elde etmiş oluruz.

\section{Konumcu Tanımlama}

Göcke’nin (2009) “konum görüşü” olarak adlandırdığı kavramsallaştırmaya göre bir şey eğer uzayda bir konuma sahipse fizikseldir. Daly bu tanımlamaya göre uzayın kendisinin fiziksel olamayacağını çünkü uzayın kendisinin uzayda bir konuma sahip olmadığını belirtiyor (Daly 1998: 204). Uzayın fizikselliği sorununu da göz önünde bulundurarak konumcu tanımlamayı şu şekilde ifade edebiliriz: Bir özellik ancak ve ancak uzayda ya da uzay tarafindan örneklenen bir özellikse fizikseldir. Uzay-olmak, uzay tarafından örneklenen bir özellik olduğundan, bu tanıma göre uzay da fiziksel olur.

Fakat, bu sefer de zamanın fizikselliği sorusu ortaya çıkıyor. Eğer zaman uzaydan ontolojik olarak bağımsızsa, konumcu tanımlamaya göre zaman fiziksel değildir. Bu durumda, konumcu tanımlamayı yalnızca uzayda değil zamanda da konumlanmaya atıfta bulunacak şekilde güncelleyebiliriz: Bir özellik ancak ve ancak uzayda (ya da uzay tarafından) veya zamanda (ya da zaman tarafından) örneklenen bir özellikse fizikseldir. Bu durumda zaman fiziksel olsa da, Montero'nun (1999: 195, n. 10) da dikkat çektiği gibi, uzayda değil yalnızca zamanda yer alan bir zihin bu tanımlamaya göre fiziksel sayılacaktır, ki bu durumda Kartezyen ikicilik fizikselci bir görüş olarak karşımıza çıkabilir, ve bu da konumcu tanımlamaya karşı bir reductio argüman teşkil edebilir. Şu formülasyonu da deneyebiliriz: Bir özellik ancak ve ancak uzayda (ya da uzay tarafindan) ve zamanda (ya da zaman tarafindan) örneklenen bir özellikse fizikseldir. Fakat, bu da sorunu çözmüyor çünkü zaman-olmak hem uzayda hem de zamanda örneklenen bir özellik değil, sadece zamanda örneklenen bir özellik. Fakat, uzayı ve zamanı ayrı ayrı ele almaktansa uzay-zaman sürekliliğine atıfta bulunarak bu 
sorunu çözebileceğimiz iddia edilebilir, çünkü hem uzay-olmak hem de zaman-olmak özellikleri uzay-zaman sürekliliği tarafından örneklenen özelliklerdir. Yani, şu fomülasyona ulaşıyoruz: Bir özellik ancak ve ancak uzay-zaman sürekliliğinde (ya da uzay-zaman sürekliliği tarafından) örneklenen bir özellikse fizikseldir. Fakat, bu durumda, Montero'nun işaret ettiği sorun yeniden kendini gösteriyor; yalnızca zamanda yer alan bir zihin bu tanımlamaya göre fiziksel sayılıyor (çünkü zaman-olmak özelliği uzay-zaman sürekliliği tarafından örnekleniyorsa zamanda-olmak özelliği de uzayzaman sürekliliğinde örnekleniyor olacaktır).

Belki sadece uzaya atıfta bulunan konumcu tanımlama, aynı via negativa tanımlamada gördüğümüz gibi, sadece zihin felsefesi bağlamında kullanılabilir ve böylece zamanın metafiziğine dair sorular bir sorun yaratmayabilir. Bu noktada, via negativa tanımlamayı mı yoksa konumcu tanımlamayı m1 tercih etmeliyiz? Hangisi fizikselcilerle ikiciler arasındaki fikir ayrılığını daha iyi yansıtıyor?

\section{Zihin-Beden Sorunu ve Zihnin Fizikselliği}

Ben gördügüumüz dört çeşit tanımlamanın her birinin fizikselcilerle ikiciler arasındaki farklı bir ayrışma noktasını vurguladığını ve bu ayrışma noktalarının hiçbirinin özü itibariyle diğerlerinden önemli olmadığını düşünüyorum. Bu yüzden de fizikseli tanımlamaya çalışmaktan ziyade fizikselcilerle ikiciler arasındaki zihnin ontolojisine dair fikir ayrılıklarını açıkça ortaya koymanın daha doğru olduğuna ve bunu yaparsak fizikseli tanımlama ihtiyacının da ortadan kalkacağına inanıyorum.

Zihin-beden sorunu, zihin ile bedenin (daha özelde beynin) ontolojik ilişkisini açıklama sorunu. $\mathrm{Bu}$ sıklıkla zihinselle fizikselin ontolojik ilişkisinin ne olduğu sorusuna denk görülüyor ve soru fizikselle zihinselin ilişkisine atıfla formüle edildiğinde fizikselin tanımını yapmak gerekiyor. Fizikseli "zihin fiziksel midir?" sorusunu açıklığa kavuşturma niyetiyle tanımlamaya çalıştı̆̆ımızda fizikselcilerle ikiciler arasındaki ayrışmayı gerçekçi şekilde yansıtması bir tanımlamanın kabul edilebilirliğinde önemli bir rol oynuyor. Ve ele aldığımız dört tanımlama da fizikselcilerle ikiciler arasındaki farklı bir ayrışmaya vurgu yapıyor. 
Bir fizikselci ile bir ikici arasındaki bazı olası anlaşmazlık noktalarını ele alalım ve bunları "fiziksel" terimini kullanmadan ifade edelim:

1. Zihin bilim tarafından açıklanabilir/açıklanamaz.

2. İnsanda, temelde, şu etrafımızda gördüğümüz masa, ağaç gibi nesnelerden ontolojik olarak farklı bir şey yoktur/vardır.

3. Zihin, zihinsel-olmayana ontolojik olarak indirgenebilir/indirgenemez.

4. Zihinsel varlığımız mekâna bağlıdır/bağlı değildir (ya da ölümden sonra mekân dışı bir boyutta bilinçli hayat mümkün değildir/mümkündür).

$\mathrm{Bu}$ anlaşmazlık noktalarından her biri ele aldığımız fiziksellik tanımlamalarından biri tarafından vurgulanıyor. Yukarıdaki anlaşmazlık noktaları için sırasıyla, kuramcı tanımlama, örnekçi tanımlama, via negativa tanımlama ve konumcu tanımlama fizikselin en uygun tanımlaması olarak karşımıza çıkıyor. Bu anlaşmazlık noktalarından hangisinin daha önemli olduğu normatif sorusu, Chalmers'ın (2011: 533-4) da ifade ettiği gibi, zihin felsefesinin dişında, sosyolojik, psikolojik, belki de tamamen öznel bir soru olduğundan, hangi fiziksel tanımının en doğru tanım olduğu sorusu da zihin felsefesinin bir sorusu olmaktan çıkıp tamamen pragmatik bir soruya dönüşüyor.

Zihin felsefesi bağlamında fizikselciliği, yukarıda listelediğimiz anlaşmazlık noktalarına ve bunlara denk düşen "fiziksel” tanımlamalarına dayanarak şu dört şekilde ifade edebiliriz:

1. Kuramcı fizikselcilik: Zihin, bilim tarafından açıklanabilir.

2. Örnekçi fizikselcilik: İnsanda, temelde, şu etrafimızda gördüğümüz masa, ağaç gibi nesnelerden ontolojik olarak farklı bir şey yoktur

3. Via negativa fizikselcilik: Zihin, zihinsel-olmayana ontolojik olarak indirgenebilir.

4. Konumcu fizikselcilik: Zihinsel varlı̆̆ımız mekâna bağlıdır.

Bu fizikselciliklerden bir kısmı doğru iken bir kısmı yanlış olabilir. Örneğin, eğer tümbilinççilik (panpsychism) doğruysa ve kategorik (işlevsel, eğilimsel ya da yapısal olmayan, bu nedenle de nicelenemeyen) bilinç özellikleri maddenin spin, yük ve kütle gibi temel özellikleri arasındaysa, kuramcı ve via negativa fizikselcilik yanlış, fakat 
örnekçi ve konumcu fizikselcilik doğru olacaktır. Şimdi, tümbilinççilik, Strawson'un (2006) iddia ettiği gibi, fizikselci bir görüş müdür, yoksa günümüz zihin felsefesinde genel olarak kabul edildiği gibi, fizikselci bir görüş değil midir? Bu, Chalmers'1n (2011) deyimiyle, sadece sözel bir tartışmadır; zihnin ontolojisine dair bir tartışma değildir. Eğer tümbilinççiliğin doğruluğu kanıtlanabilirse, "tümbilinççilik fizikselci bir görüş müdür?” sorusunun (ve bunun arkaplanında yatan "yukarıda listelenen fizikselcilik tanımlamalarından hangisi gerçek fizikselciliktir?" sorusunun) cevabı bize zihnin ontolojisine dair yeni hiçbir şey söylemeyecektir.

Ele aldığımız her fiziksel tanımlamasına, bazıları diğerlerinden daha ciddi olmakla birlikte, itirazlarda bulunduğumuzu da göz önünde bulundurarak, zihin-beden sorununu zihnin fiziksel olup olmaması sorusu şeklinde ifade etmekten vazgeçmemiz gerektiğini düşünüyorum. "Fiziksel” terimini kullanmanın her bağlamda büyük sorunlar doğurduğunu iddia etmiyorum, fakat zihin felsefesi tartışmalarında genel olarak felsefeciler arasındaki diyaloğu zorlaştırdığı kanaatindeyim. Fizikseli tanımlama ihtiyacı hissedildiği anda "fiziksel" terimini unutup, ayrışma noktası her neyse oraya odaklanmak çok daha verimli olacaktır. Yukarıda listelediğim dört fizikselci iddiayı formüle etmek ve doğruluğunu değerlendirmek için "fiziksel” teriminin kullanılması gerekmediği gibi, bu iddialara dair sorgulamamızı sonuçlandırabilirsek "zihin fiziksel midir?" sorusu da anlamını yitirecektir.

Eğer, zihin felsefesi bağlamında, "fiziksel” teriminden vazgeçersek, "fizikselcilik" teriminden de vazgeçmemiz uygun olacağından, yukarıda belirttiğim olası fizikselcilik tanımlamaları için şu terimleri öneriyorum: "Kuramcı-fizikselcilik" yerine "Bilimselcilik"; "Örnekçi fizikselcilik" yerine "Olağancılık"; "Via negativa fizikselcilik" yerine "Bilinçötecilik"; "Konumcu fizikselcilik" yerine "Konumculuk".

\section{Sonuç}

Zihin-beden sorununun birçok felsefeci tarafından zihinselle fizikselin ontolojik ilişkisini açıklığa kavuşturma sorunu olarak ele alınması ve bu konudaki temel görüşlerden birinin "fizikselcilik" olarak anılıyor olması "fiziksel”in tanımlanması 
ihtiyacını doğuruyor. Fakat, zihnin fizikselliğinin sorgulanmasının ardında zihnin doğasına ve doğadaki yerine dair farklı sorular yatabiliyor -ki bunların en önde gelen dört tanesini inceledik- ve bu soruları "fiziksel" terimini kullanarak sormak istediğimizde, birbiriyle uyuşmayan, bazen de kendi içinde kabul edilebilir olmayan, farklı fiziksellik tanımlamalarını kullanmamız gerekiyor. Bu noktada artık "fiziksel" terimi diyaloğu ve anlaşmayı kolaylaştırmayan, tam tersine zorlaştıran bir rol oynamaya başladığından, zihin felsefesi bağlamında bu terimi kullanmaktan kaçınmanın ve zihnin fizikselliği sorununu farklı şekillerde ifade etmenin daha yararlı olacağını düşünüyorum. 


\section{KAYNAKÇA}

ARMSTRONG, David M. (1970). "The Nature of Mind." The Mind/Brain Identity Theory, ed. Clive V. Borst, Macmillan.

ARMSTRONG, David M. (1993). "A World of States of Affairs." Philosophical Perspectives. Vol. 7, Language and Logic, pp. 429-440

BOHR, Niels (1934). Atomic Theory and the Description of Nature. Cambridge: Cambridge University Press. (Re-issued in 1961) Wiley.

BOHR, Niels (1958). Atomic Physics and Human Knowledge. New York:

BOKULICH, Peter (2011). "Hempel's Dilemma and Domains of Physics." Analysis, 71(4)/2011: 646-651.

CHALMERS, David J. (2011). "Verbal Disputes." Philosophical Review, 120(4)/2011: 515-566.

CHALMERS, D. J. \& F. JACKSON (2001). "Conceptual analysis and Reductive Explanation,” Philosophical Review, 110/2011: 315-360.

CHOMSKY, N. (1995). “Language and Nature,” Mind, 104/1995: 1-61. University Press.

CORNMAN, J. (1971). Materialism and Sensations, New Haven: Yale

CRANE, Tim \& D. H. MELLOR (1990). "There Is No Question of Physicalism," Mind, 99(394)/1990: 185-206.

DALY, Chris (1998). "What are Physical Properties?", Pacific Philosophical Quarterly, 79(3)/1990: 196-217.

DERKSEN, A. A. (1993). "The Seven Sins of Pseudoscience," Journal for General Philosophy of Science, 24/1993: 17-42.

GOLDSTEIN, S. (2017) "Bohmian Mechanics", The Stanford Encyclopedia of Philosophy (Summer 2017 Edition), Edward N. Zalta (ed.). 307.

GOCKE, Benedikt Paul (2009) “What Is Physicalism?”, Ratio, 22(3)/2009: 291-

HEISENBERG, Werner (1958). "The Representation of Nature in Contemporary Physics," Daedalus, 87/1958: 95-108

HOWELL, Robert J. (2008). "Subjective Physicalism," The Case for Qualia. ed. Edmond Wright, MIT Press.

JACKSON, Frank (1982). "Epiphenomenal Qualia," The Philosophical Quarterly, 32(127)/1982: 127-136. doi:10.2307/2960077. 
JACKSON, Frank (1986). "What Mary Didn't Know," The Journal of Philosophy, 83(5)/1986: 291-295. doi:10.2307/2026143.

JACKSON, Frank. (2000). From Metaphysics to Ethics: A Defense of Conceptual Analysis, Oxford University Press.

KIYMAZ, Tufan (2019a) "Phenomenal Concepts and Physical Facts: A Dialogue with Mary," Filozofia: Journal for Philosophy, 74(10)/2019: 797-807.

KIYMAZ, Tufan (2019b) "Subjective Physicalism as a Response to the Knowledge Argument," MetaZihin. 2(2)/2019: 199-211.

KIYMAZ, Tufan (2020) "A Priori Physicalism and the Knowledge Argument," Teorema, 39(2)/2020: 87-103.

KIYMAZ, Tufan (Yayınlanacak) "On the Paradigmatic Conception of the Physical," Problemos.

LEVINE, Joseph (1983). "Materialism and qualia: The Explanatory Gap," Pacific Philosophical Quarterly, 64/1983: 354-361.

LOEWER, Barry M. (2001). "From Physics to Physicalism," Physicalism and its Discontents, ed. Carl Gillett \& Barry M. Loewer, Cambridge University Press.

MELNYK, Andrew (1997). "How to Keep the 'Physical' in Physicalism," The Journal of Philosophy, 94 (12): 1997: 622-637.

MONTERO, Barbara (1999). “The Body Problem,” Nous, 33/1999: 183-200.

NAGEL, Thomas (1974). "What is it like to be a bat?" Philosophical Review, 83/1974: 435-50.

POLAND, Jeffrey (2003). "Chomsky's Challenge to Physicalism," Chomsky and His Critics, pp. 29-48, ed. Louise M. Antony, Malden Ma: Blackwell.

SMART, J. J. C. (1978). "The Content of Physicalism," Philosophical Quarterly, 28/1978: 339-41.

SMITH, A. D. (1993). "Non-reductive Physicalism?," Objections to Physicalism, ed. H. Robinson. Oxford: Clarendon Press.

SNOWDON, Paul (1989) "On Formulating Materialism and Dualism”, Cause, Mind, and Reality: Essays in Honour of C.B.Martin, pp. 137-158, ed. John Heil, Dordrecht: Kluwer Press.

SPURRETT, D. \& D. PAPINEAU (1999). "A note on the Completeness of 'Physics"', Analysis, 59(1)/1999: 25-29.

STAPP, Henry (2007). "Quantum Mechanical Theories of Consciousness." A Companion to Consciousness, pp. 300-312, ed. Max Velmans \& Susan Schneider, Blackwell.

STOLJAR, Daniel (2001). "Two Conceptions of the Physical," Philosophy and Phenomenological Research, 62(2)/2001: 253-281. 
STRAWSON, Galen (2006). "Realistic Monism: Why Physicalism Entails Panpsychism," Journal of Consciousness Studies, 13(10-11)/2006: 3-31.

TYE, Michael (2009). Consciousness Revisited: Materialism Without Phenomenal Concepts. MIT Press.

WILSON, Jessica M. (2006).“On Characterizing the Physical,” Philosophical Studies, 131(1)/2006: 61-99.

VON NEUMANN, J. (1955). Mathematical Foundations of Quantum Mechanics. Princeton. 